\title{
Triptolide inhibits epithelial-mesenchymal transition and induces apoptosis in gefitinib-resistant lung cancer cells
}

\author{
FANGQIONG LI ${ }^{1}$, HUAIZHONG CUI ${ }^{2}$, XIN JIN $^{1}$, XIAOTING GONG ${ }^{1}$, WEI WANG ${ }^{1 *}$ and JUAN WANG ${ }^{1 *}$ \\ ${ }^{1}$ Department of Clinical Laboratory, Tongde Hospital of Zhejiang Province, Hangzhou, Zhejiang 310012; \\ ${ }^{2}$ Department of Clinical Laboratory, XiXi Hospital of Hangzhou, Hangzhou, Zhejiang 310023, P.R. China
}

Received October 15, 2019; Accepted January 29, 2020

DOI: $10.3892 /$ or.2020.7542

\begin{abstract}
The epidermal growth factor receptor-tyrosine kinase inhibitor (EGFR-TKI), gefitinib, is used widely to treat non-small cell lung cancer (NSCLC) with EGFR-activating mutations. Unfortunately, the acquired drug resistance promoted by epithelial-mesenchymal transition (EMT) markedly limits the clinical effects and remains a major barrier to a cure. Our previous isobaric tags for relative and absolute quantitation-based proteomics analysis revealed that the E-cadherin protein level was markedly upregulated by triptolide (TP). The present study aimed to determine whether TP reverses the gefitinib resistance of human lung cancer cells by regulating EMT. It was revealed that TP combined with gefitinib synergistically inhibited the migration and invasion of lung adenocarcinoma cell line A549; the combination treatment had a significantly better outcome than that of TP and gefitinib alone. Moreover, TP effectively increased the sensitivity of drug resistant A549 cells to gefitinib by upregulating E-cadherin protein expression and downregulating the MMP9, SNAIL, and vimentin expression levels. The dysregulated E-cadherin expression of gefitinib-sensitive cells induced gefitinib resistance, which could be overcome by TP. Finally, TP combined with gefitinib significantly inhibited the growth of xenograft tumors induced using gefitinib-resistant A549 cells, which was associated with EMT reversal and E-cadherin signaling activation in vivo. The present results indicated that the combination of TP and TKIs may be a promising therapeutic strategy to treat patients with NSCLCs harboring EGFR mutations.
\end{abstract}

Correspondence to: Dr Juan Wang or Professor Wei Wang, Department of Clinical Laboratory, Tongde Hospital of Zhejiang Province, 234 Gucui Road, Hangzhou, Zhejiang 310012, P.R. China

E-mail: wangjuanzju@163.com

E-mail: wangweihz8@163.com

${ }^{*}$ Contributed equally

Key words: triptolide, gefitinib, NSCLC, E-cadherin, EMT

\section{Introduction}

Lung cancer is the one of the leading causes of cancer mortality in the world, and non-small-cell lung cancer (NSCLC) accounts for nearly $85 \%$ of all lung cancers (1). Gefitinib, a typical reversible EGF receptor tyrosine kinase inhibitor (EGFR-TKI), has a marked therapeutic effect in NSCLC patients with EGFR mutations, and has been used widely as the first-choice treatment for NSCLC $(2,3)$. However, despite the excellent initial clinical responses, almost all responding patients eventually develop different degrees of resistance within one year (2-4). Hence, reversal of the resistance to EGFR-TKIs is an urgent requirement for lung cancer therapy.

In recent years, certain Chinese herbal medicines have exhibited notable effects on drug resistance (5). Previous studies have found that curcumin (6), scorpion venom (7) and bufalin (8) could delay the emergence of EGFR-TKI resistance or inhibit drug resistance via different signaling pathways. Clinical trials have begun to utilize Chinese herbal medicines combined with EGFR-TKIs to treat lung cancer.

Among the Chinese herbal medicines, triptolide (TP), a purified diterpenoid from Tripterygium wilfordii Hook.f. (TWHF), exhibits promising potential in reversing drug resistance (9). Previous studies confirmed that TP has many biological properties, including immunosuppressive and anti-inflammatory effects (10). An increasing number of preclinical studies have demonstrated that TP has strong antitumor activities. As an adjuvant therapeutic agent, TP has been revealed to enhance the effect of some anticancer agents at low doses, such as hydroxycamptothecin (11) and fluorouracil (12), and increase the sensitivity of drug resistant cells to chemotherapeutics $(9,13,14)$, rendering the combination superior to mono-therapy. However, the molecular mechanisms by which TP induces inhibition of drug resistance and sensitization are unclear. Previously, we used high-sensitivity isobaric tags for a relative and absolute quantitation technique and observed that TP treatment caused abnormal expression of proteins involved in a variety of biological processes. In particular, the increase in E-cadherin was particularly pronounced (15). E-cadherin is a core protein of epithelial-mesenchymal transition (EMT) and is involved in cancer invasion and metastasis (16). E-cadherin is closely related to molecular treatment targeting EGFR resistance and sensitivity. Increased expression of E-cadherin enhanced the sensitivity of tumor cells to the EGFR inhibitor 
gefitinib, while knockdown of E-cadherin in parental cells induced gefitinib resistance and stemness (17-19). Thus, it was speculated that E-cadherin may participate in the development of sensitivity or resistance to EGFR-TKIs, and play a role in the complex intercellular regulation.

In the present study, it was revealed that TP combined with gefitinib had a synergistic inhibitory effect on the proliferation, migration, and invasion of A549 cells, which are resistant to gefitinib. The effect of TP against gefitinib resistance was attributed to its ability to reverse EMT by upregulating E-cadherin levels and inhibiting cell proliferation. In addition, this combinational therapy reduced the tumor volume more effectively than gefitinib or TP alone in a xenograft mouse model, and this synergistic interaction was associated with the ability of TP to reverse EMT. Thus, evidence is provided that the combination of TP and gefitinib could overcome TKI resistance in patients with NSCLC with EGFR mutations and could lead to the development of new combinatorial therapies for lung cancer.

\section{Materials and methods}

Chemicals. TP was purchased from Sigma-Aldrich; Merck $\mathrm{KGaA}$. The molecular formula of TP is $\mathrm{C}_{20} \mathrm{H}_{24} \mathrm{O}_{6}$, it has a molecular weight of $360.4 \mathrm{Da}$, and a purity $\geq 98 \%$. Gefitinib was also purchased from Sigma-Aldrich; Merck KGaA. The molecular formula of gefitinib is $\mathrm{C}_{22} \mathrm{H}_{24} \mathrm{ClFN}_{4} \mathrm{O}_{3}$, it has a molecular weight of $446.90 \mathrm{Da}$ and purity $\geq 98 \%$. Both TP and gefitinib were stored in dimethyl sulfoxide (DMSO) at $100 \mu \mathrm{g} / \mathrm{ml}$ at $-80^{\circ} \mathrm{C}$ and diluted to the indicated concentrations using serum-free culture medium.

Cell line and culture. Human lung cancer A549 (American Type Culture Collection; ATCC ${ }^{\circledR}$ CCL185 $^{\mathrm{TM}}$ ) cells were purchased from Meixuan Biological Science Co., Ltd. (identification number MXC026). The cells were maintained in 90\% Dulbecco's modified Eagle's medium (DMEM, Gibco; Thermo Fisher Scientific, Inc.) supplemented with $10 \%$ fetal bovine serum (Gibco; Thermo Fisher Scientific, Inc.), L-glutamine $(2 \mathrm{mM}), 1 \%$ penicillin-streptomycin $(100 \mathrm{U} / \mathrm{ml}$ penicillin and $100 \mu \mathrm{g} / \mathrm{ml}$ streptomycin), and HEPES (25 mM) according to the supplier's instruction manual. Cells were incubated in a humid incubator containing $5 \% \mathrm{CO}_{2}$ at $37^{\circ} \mathrm{C}$.

The gefitinib-resistant human lung adenocarcinoma cell line $(\mathrm{A} 549 / \mathrm{G})$ was established by increasing the gefitinib concentration. Briefly, A549 cells with $80 \%$ fusion were first treated with $5 \mu \mathrm{g} / \mathrm{ml}$ gefitinib for $24 \mathrm{~h}$. The surviving cells were cultured for further cycles with increased doses of gefitinib $(10 \mu \mathrm{g} / \mathrm{ml}$ and $15 \mu \mathrm{g} / \mathrm{ml})$, until the A549 cells grew steadily in the medium with $15 \mu \mathrm{g} / \mathrm{ml}$ gefitinib. The resistance index of A549/G was detected using a Cell Counting Kit-8 assay (Beyotime Institute of Biotechnology), and calculated according to the equation of the half maximal inhibitory concentration: $\mathrm{IC}_{50}(\mathrm{~A} 549 / \mathrm{G}) / \mathrm{IC}_{50}$ (A549), which provided a resistance index of 5.48 .

Another gefitinib-resistant human lung adenocarcinoma cell line (A549/siE-cad) was established using lentivirus-mediated small hairpin RNA (shRNA) to attenuate E-cadherin (CDH1) expression in the A549 cell line. The shRNA targeting $\mathrm{CDHI}$ was cloned into the pLV-shRNA-EGFP (2A) Puro vector. The
shRNA sequence for $C D H 1$ was as follows: GGATCC-GCC CACAGATCCATTTCTTGCTCGAGCAAGAAATGGATC TGTGGGTTTTT-GAATTC. The generated vectors were confirmed by DNA sequencing.

Transfection. The 293T cells were cultured in 10-cm dishes at a density of $4.0 \times 10^{6}$. Then, $500 \mu \mathrm{l}$ of opti-MEM containing $5 \mu \mathrm{g}$ of lentiviral interference vector targeting E-cadherin, $3.75 \mu \mathrm{g}$ of $\mathrm{pH} 1$ vector, and $1.25 \mu \mathrm{g}$ of $\mathrm{pH} 2$ vector was added into $500 \mu \mathrm{l}$ of opti-MEM including $20 \mu \mathrm{l}$ of Lipofectamine 2000, the mixture was incubated at room temperature for $20 \mathrm{~min}$ and added dropwise to the $293 \mathrm{~T}$ cells. The medium was replaced with serum-free DMEM at $5 \mathrm{~h}$ post-transfection. The lentiviral particles were harvested by ultracentrifugation at $82,700 \mathrm{xg}$ for $48 \mathrm{~h}$ after transfection. Cells were infected with the harvested lentiviruses (siE-cad) at a multiplicity of infection (MOI) of 20. The optimal infection condition was confirmed by observing the cells expressing the green fluorescent protein at $72 \mathrm{~h}$ after infection. Puromycin $(2 \mu \mathrm{g} / \mathrm{ml})$ was used to screen for stably infected cells. The resistance index of cells with stably interfered $C D H 1$ (A549/siE-cad) was detected by Cell Counting Kit-8, and calculated, according to the equation: $\mathrm{IC}_{50}(\mathrm{~A} 549 / \mathrm{siE}-\mathrm{cad}) / \mathrm{IC}_{50}$ (A549), providing a resistance index of 2.95 .

Mouse model. Male BALB/c mice (4 weeks old) were obtained from Shanghai SLAC Laboratory Animal Co., Ltd. [SCXK (HU) 2017-0005]. The body weight ranged from 18 to $22 \mathrm{~g}$. All mice were fed with standard mouse food and tap water and maintained under conditions of $25^{\circ} \mathrm{C}$ with a 12-hour light/dark cycle. The A549/siE-cad cells $\left(2 \times 10^{6}\right)$ were injected subcutaneously into the underarms of the right forelimbs of 6-week-old $\mathrm{BCLB} / \mathrm{c}$ mice. After 3 weeks, all mice were randomly divided into four groups of five. These mice were administered with drugs or saline (mock) via abdominal administration every day for 4 weeks as follows: The control group was administered with $\mathrm{NaCl}[0.01 \mathrm{ml} / \mathrm{g}$ body weight $(\mathrm{BW})]$, the TP-treated group was administered with $\mathrm{TP}(0.5 \mathrm{mg} / \mathrm{kg} \mathrm{BW})$, the gefitinib-treated group (G) with gefitinib (50 $\mathrm{mg} / \mathrm{kg} \mathrm{BW})$, the $\mathrm{TP}+\mathrm{G}$ group with $\mathrm{TP}(0.5 \mathrm{mg} / \mathrm{kg} \mathrm{BW})$ and gefitinib (50 mg/kg BW). The body weight and tumor size were recorded every two days; the tumor volume was calculated as: A x b x b/2 $\left(\mathrm{mm}^{3}\right.$ ) (a indicated the long diameter, and $b$ the short diameter). Subsequently euthanasia was performed in accordance with the Guidelines for Euthanasia of Rodents Using Carbon Dioxide issued by the National Institutes of Health. At the end of 4 weeks, all animals were euthanized by carbon dioxide in their home cage placed in special transparent chambers. The chambers were connected with compressed carbon dioxide in a gas cylinder and flow controller. The gas replacement rate was $28 \%$ of container volume/min. Death was further verified by cardiac arrest and cadaveric rigidity. Their tumors were collected, paraffin-embedded, and then serially sectioned for subsequent hematoxylin staining and immunohistochemistry (IHC).

Cell Counting Kit-8 assays (CCK-8). The viability of cells treated with different drugs was detected using CCK-8 assay (Beyotime Institute of Biotechnology). The A549 cells were exposed to various concentrations of TP $(0,1,2,4,8,16$ and $32 \mathrm{ng} / \mathrm{ml})$ and gefitinib $(0,0.627,1.25,2.5,5,10$ and $20 \mu \mathrm{g} / \mathrm{ml})$, 
alone or in combination, for 24,36 and $48 \mathrm{~h}$, respectively, as indicated. Cell viability was evaluated according to manufacturer's instructions. The combination index (CI), resistance index (RI), and $\mathrm{IC}_{50}$ values were calculated based on the data from the cell viability assays. The optimal combined concentration of TP and gefitinib was determined by $\mathrm{CI}<1$, which indicated that the effect of two drugs was synergistic. The RI equation was as follows: $\mathrm{IC}_{50}(\mathrm{~A} 549 / \mathrm{G}) / \mathrm{IC}_{50}$ (A549), or $\mathrm{IC}_{50}$ (A549/siE-cad)/IC ${ }_{50}$ (A549).

Cell migration and invasion. Cell migration and invasion were determined using a Transwell system (product no. 3422; Corning, Inc.) with $8.0-\mu \mathrm{m}$ diameter pores. For the invasion assays, $45 \mu \mathrm{l}$ diluted Matrigel was pre-coated on the Transwell membranes. A total of $5 \times 10^{4}$ cells were seeded into the upper chamber, and $20 \%$ FBS-containing medium was seeded into the lower chamber to induce cell migration and invasion. After 12 or $48 \mathrm{~h}$ of incubation ( $12 \mathrm{~h}$ for the migration assays and $48 \mathrm{~h}$ for the invasion assays), the cells on the upper surface of the filter were removed, and then the residual cells in the Transwell chambers were fixed with $4 \%$ paraformaldehyde at $4^{\circ} \mathrm{C}$ for $10 \mathrm{~min}$, stained with crystal violet $(0.1 \%, \mathrm{w} / \mathrm{v})$ at room temperature for $5 \mathrm{~min}$, and photographed under a microscope (Olympus Corp.). Five fields were selected at random, and the number of cells was counted in each field. Experiments were performed three times independently.

Western blot analysis. The prepared cells were harvested to extract proteins by enhanced RIPA lysis buffer (P0013B; Beyotime Institute of Biotechnology), and its components included $50 \mathrm{mM}$ Tris ( $\mathrm{pH} 7.4$ ), $150 \mathrm{mM} \mathrm{NaCl}, 1 \%$ Triton X-100, $1 \%$ sodium deoxycholate, $0.1 \%$ SDS, sodium orthovanadate, sodium fluoride, EDTA, leupeptin and protease inhibitors. The concentration was determined using a BCA protein assay kit (735094; Roche Diagnostics). The proteins $(20 \mu \mathrm{g})$ were separated using $8 \%$ SDS-PAGE and then transferred to a nitrocellulose membrane (Bio-Rad Laboratories, Inc.). The membrane was then incubated with the target primary antibodies E-cadherin (dilution 1:1,000; product code Ab4077; Abcam) MMP9 (dilution 1:1,000; product code Ab38898; Abcam), GAPDH (dilution 1:5,000; product code Ab8245; Abcam), caspase-3 (dilution 1:1,000; product no. 9662; Cell Signaling Technology), vimentin (dilution 1:1,000; product no. 3932; Cell Signaling Technology), Snail (dilution 1:1,000; product no. 3879; Cell Signaling Technology) and cleaved caspase-3 (dilution 1:1,000; product no. 9654; Cell Signaling Technology) at $4^{\circ} \mathrm{C}$ overnight. After washing three times with Tris-buffered saline Tween-20 buffer, the membrane was incubated with secondary antibodies: Anti-rabbit IgG HRP-linked (dilution 1:2,000; product no. 7074; Cell Signaling Technology, Inc.; for Snail, vimentin, caspase-3 and cleaved caspase-3); goat anti-rabbit IgG H\&L (HRP) (dilution 1:6,000; product code Ab205718; Abcam; for MMP-9 and E-cadherin); goat anti-mouse IgG H\&L (HRP) (dilution 1:6,000; product code Ab205719; Abcam; for GAPDH) at room temperature for $2 \mathrm{~h}$. Immune complexes were visualized using an enhanced chemiluminescence detection system (EMD Millipore).

Hematoxylin-eosin $(H \& E)$ staining. The collected tumor slides were dewaxed and rehydrated. H\&E staining was performed and then the samples were observed under a light microscope to assess their morphology.

Terminal deoxynulceotidyl transferase nick-end-labeling (TUNEL). A TUNEL kit was used (product no. 11684817910; Roche Diagnostics) as described by the manufacturer. The collected tumor slides were dewaxed and rehydrated. Endogenous peroxidase activity was blocked using 3\% hydrogen peroxide for $5 \mathrm{~min}$. The samples were then washed with phosphate-buffered saline (PBS) at room temperature and incubated in the TUNEL Reaction Mixture at $37^{\circ} \mathrm{C}$. Thereafter, incubation with converter-POD solution was carried out at $37^{\circ} \mathrm{C}$. Next, the slides were incubated with diaminobenzydine (DAB) and stained with hematoxylin. Samples were dehydrated using graded ethanol, vitrified with dimethylbenzene and deposited in neutral resins. Finally, the samples were observed under a light microscope.

Immunohistochemistry. The collected tumor slides were first dewaxed and then rehydrated. The slides were incubated in citrate buffer $(0.01 \mathrm{~mol} / \mathrm{l}, \mathrm{pH} 6.0)$ for antigen retrieval. Endogenous peroxidase activity was inhibited by using $0.3 \%$ hydrogen peroxide for $15 \mathrm{~min}$. Primary antibodies against E-cadherin (product code ab40772; Abcam), matrix metalloproteinase-9 (MMP9) (product code ab38898; Abcam), and caspase-3 (product number 9664; Cell Signaling Technology, Inc.) were incubated with the slides at $4^{\circ} \mathrm{C}$ overnight in a humidity chamber. After five washes with PBS, the slides were incubated with secondary antibodies: Goat anti-rabbit IgG H\&L, HRP-linked antibody (dilution 1:5,000; product code Ab205718; Abcam; for E-cadherin and MMP9); Signal Stain Bosst IHC detection reagent HRP-linked antibody rabbit (dilution 1:2,000; product no. 8114; for caspase-3) at room temperature for $30 \mathrm{~min}$. The tumor samples on the slides were stained with hematoxylin, dehydrated by graded ethanol, vitrified by dimethylbenzene, and deposited in neutral resins. Finally, the samples were observed and quantified under a light microscope.

Statistical analysis. The results are expressed as the means \pm SD. One or two-way ANOVA followed by Tukey's, Dunnett's and Sidak's multiple comparisons test in GraphPad Prism 6 (GraphPad Software) were used to analyze the statistical significance between two groups. A P-value $<0.05$ was considered to indicate a statistically significant difference.

\section{Results}

Combined treatment with TP and $G$ induces enhanced inhibition of A549 cell viability. First, the effect of TP or G alone was assessed on the A549 cells. As revealed in Fig. 1A, both TP and $\mathrm{G}$ induced a marked dose-dependent inhibition of A549 cell viability, and the combined treatment with TP and $\mathrm{G}$ induced a significantly increased inhibition of A549 cell viability compared to $\mathrm{TP}$ or $\mathrm{G}$ alone. The inhibitory effect of $\mathrm{TP}$ and $\mathrm{G}$ alone gradually increased with prolonged exposure time (Fig. 1B and C). The $50 \%$ growth inhibition $\left(\mathrm{IC}_{50}\right)$ at $48 \mathrm{~h}$ for TP and $\mathrm{G}$ was $10.985 \mathrm{ng} / \mathrm{ml}$ and $5.801 \mu \mathrm{g} / \mathrm{ml}$ respectively. Next, the combined effect of TP and G were evaluated, and the data revealed similar dose- and time-dependent inhibitory 
Table I. CI and $\mathrm{IC}_{50}$ analysis for $\mathrm{TP}$ and $\mathrm{G}$ combination treatment in A549 cells.

\begin{tabular}{|c|c|c|c|c|c|}
\hline \multirow[b]{3}{*}{ Exposure time (h) } & \multicolumn{4}{|c|}{$\mathrm{IC}_{50}$} & \multirow[b]{3}{*}{$\mathrm{CI}$} \\
\hline & \multirow[b]{2}{*}{$\mathrm{TP}(\mathrm{ng} / \mathrm{ml})$} & \multirow[b]{2}{*}{$\mathrm{G}(\mu \mathrm{g} / \mathrm{ml})$} & \multicolumn{2}{|c|}{$\mathrm{TP}+\mathrm{G}$} & \\
\hline & & & $\mathrm{TP}(\mathrm{ng} / \mathrm{ml})$ & $\mathrm{G}(\mu \mathrm{g} / \mathrm{ml})$ & \\
\hline 24 & 21.35 & 10.10 & 9.27 & 5.80 & 1.01 \\
\hline 36 & 16.05 & 8.87 & 7.99 & 4.99 & 1.06 \\
\hline 48 & 10.99 & 5.80 & 4.23 & 2.64 & 0.84 \\
\hline
\end{tabular}

CI, combination index; TP, triptolide; G, gefitinib.
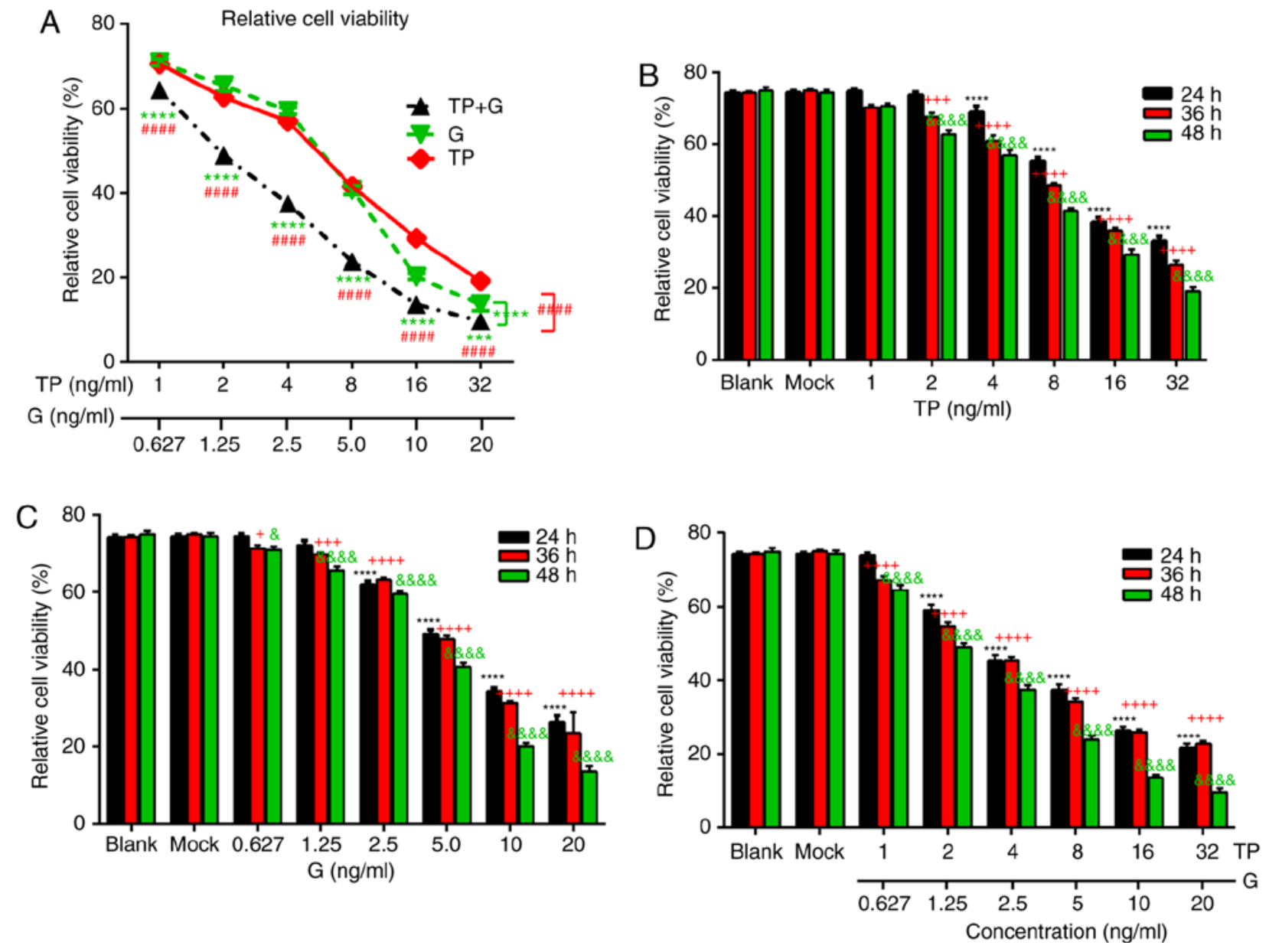

Figure 1. Effect of TP and G, alone or in combination, on A549 cell viability. (A) A549 cells were treated with the indicated concentrations of TP (1, 2, 4, 8, 16, and $32 \mathrm{ng} / \mathrm{ml})$ and $\mathrm{G}(0.627,1.25,2.5,5,10$, and $20 \mu \mathrm{g} / \mathrm{ml})$ alone or in combination for $24 \mathrm{~h}$, Green '*' indicates statistical differences between 'TP+G' and 'G', and the red ' $\#$ ' represents statistical differences between 'TP+G' and TP. (B) The individual effects of TP on A549 cell growth at 24,36, and 48 h. A549 cells were treated with graded concentrations of TP $(1,2,4,8,16$, and $32 \mathrm{ng} / \mathrm{ml}$, respectively). Statistical differences between mock and treated groups at 24,36 and $48 \mathrm{~h}$ were respectively indicated with black '*', red ' + ' and green ' $\&$ '. (C) The individual effects of G on A549 cell growth at 24, 36, and 48 h. A549 cells were treated with graded concentrations of G $(0.627,1.25,2.5,5,10$, and $20 \mu \mathrm{g} / \mathrm{ml}$, respectively). Statistical differences between mock and treated groups at 24,36 and $48 \mathrm{~h}$ were respectively indicated with black '*', red 't' and green ' $\&$ '. (D) The combined effects of TP and G on A549 cell growth at 24, 36, and 48 h. A549 cells were treated with the combined concentrations of TP $(1,2,4,8,16$, and $32 \mathrm{ng} / \mathrm{ml}$, respectively) and $\mathrm{G}(0.627,1.25,2.5,5,10$, and $20 \mu \mathrm{g} / \mathrm{ml}$, respectively). Statistical differences between mock and treated groups at 24,36 and $48 \mathrm{~h}$ were respectively indicated with black '*', red ' + ' and green ' $\&$ '. Two-way ANOVA followed by Tukey's and Dunnett's multiple comparisons test were used to analyze differences between groups. TP, triptolide; G, gefitinib.

effects on the $\mathrm{A} 549$ cells, with an $\mathrm{IC}_{50}$ for $\mathrm{TP} 4.228 \mathrm{ng} / \mathrm{ml}$, and an $\mathrm{IC}_{50}$ for $\mathrm{G}$ of $2.644 \mu \mathrm{g} / \mathrm{ml}$ at $48 \mathrm{~h}$ (Fig. 1D). These results indicated that TP had a similar inhibitory effect to $\mathrm{G}$ on the proliferation of A549 cells, and the combined treatment comprising TP and G more effectively inhibited A549 cell growth than TP or G alone. 
A

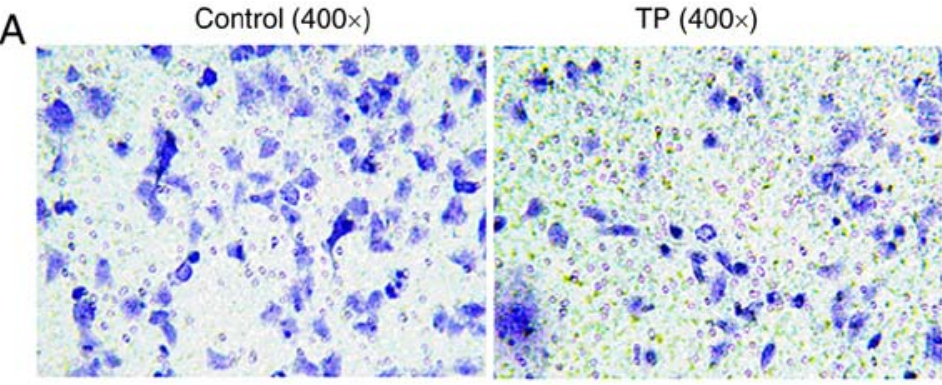

$\mathrm{G}(400 \times)$

\section{$\mathrm{TP}+\mathrm{G}(400 \times)$}
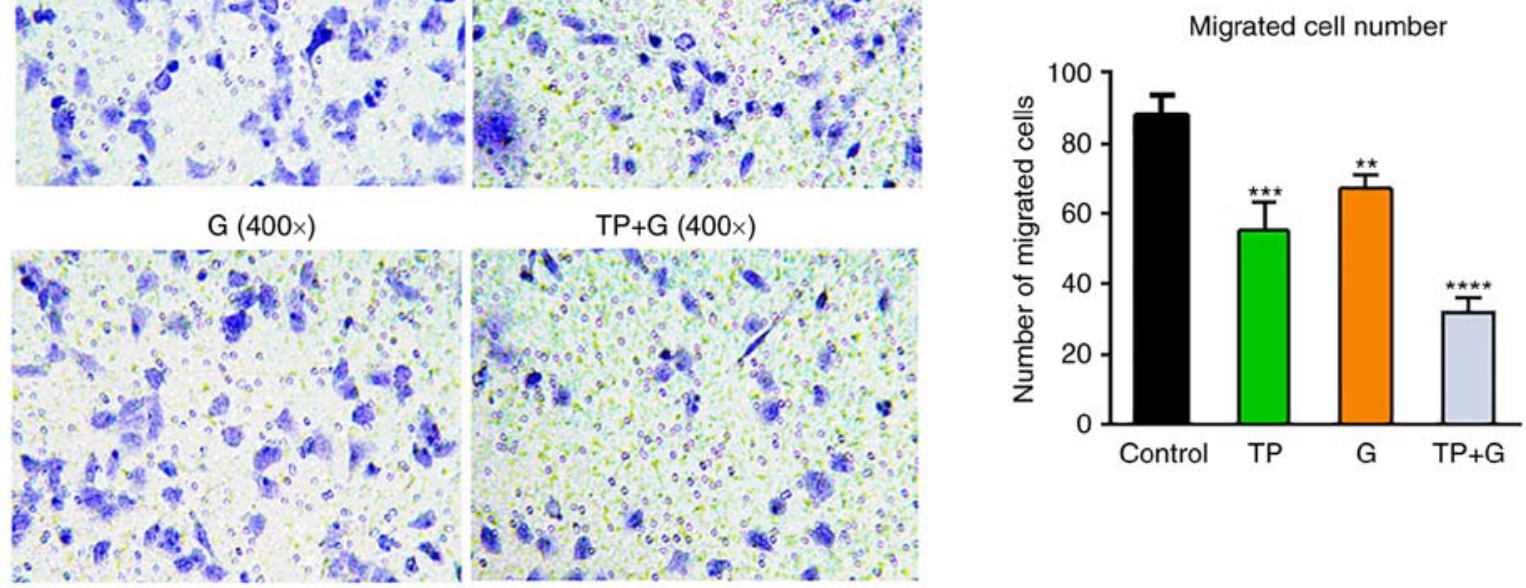

Figure 2. TP and G synergistically suppress the migration of A549 cells. (A) A549 cells were treated with TP (2 ng/ml) and G (1.25 $\mu \mathrm{g} / \mathrm{ml})$ alone or in combination for $12 \mathrm{~h}$ and then stained with crystal violet. The images were representative of three independent experiments (A). The absolute number of migrated cells is presented as the means $\pm \mathrm{SD}(\mathrm{B})$. Comparisons between mock and treated groups were performed by one-way ANOVA followed by Dunnett's multiple comparisons test. Statistical differences between the control and treated groups were represented by black '*'. TP, triptolide; G, gefitinib.

A

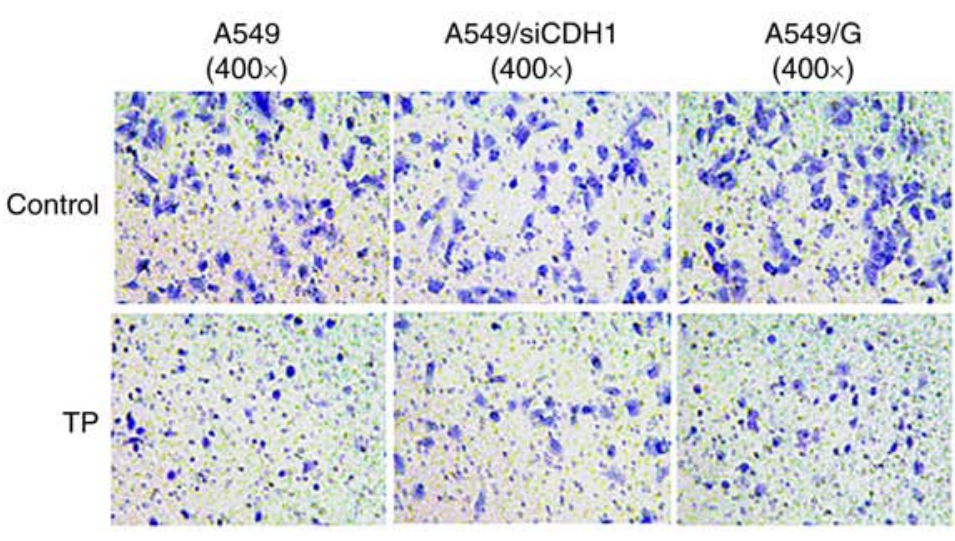

B

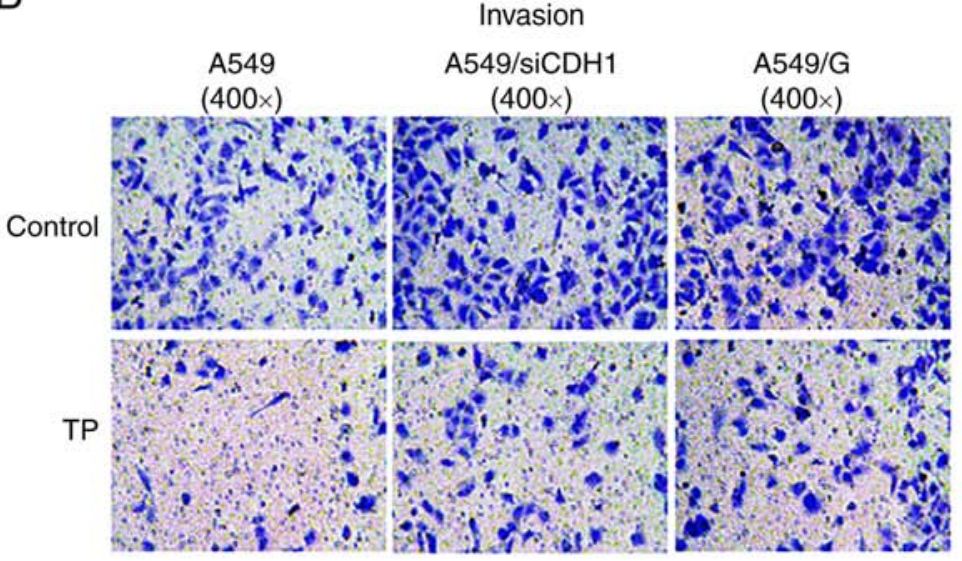

Migrated cell number

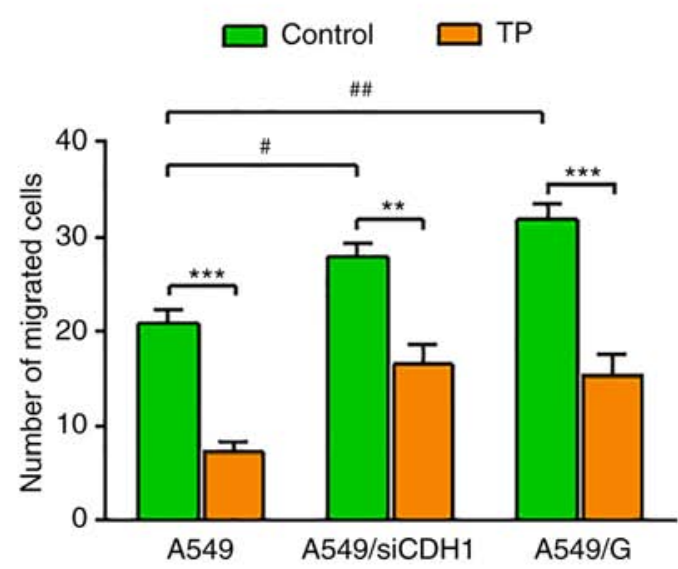

Invaded cell number

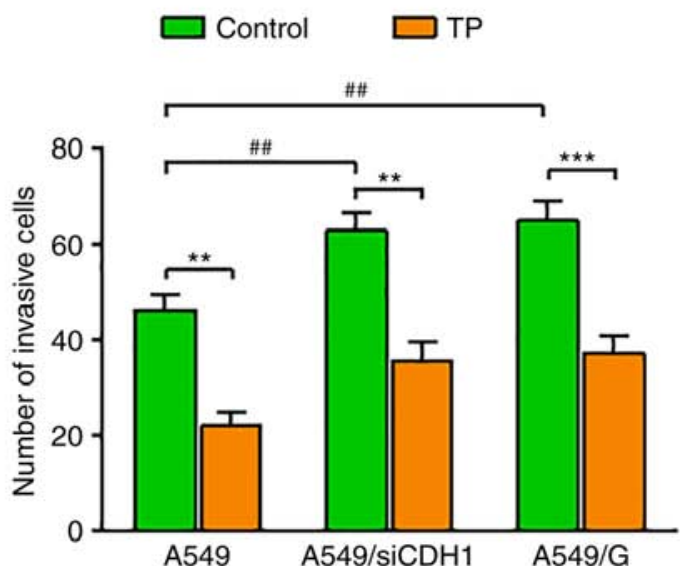

Figure 3. TP suppresses the migration and invasion of A549 cells. Transwell (A) migration and (B) invasion assays of A549 cells treated with TP (2 ng/ml). The absolute number of migrated or invaded cell is presented as the means \pm SD from three independent experiments. Two-way ANOVA followed by Sidak's and Dunnett's multiple comparisons test were used to analyze differences between two groups. TP, triptolide; G, gefitinib; CDH1, E-cadherin. 
A

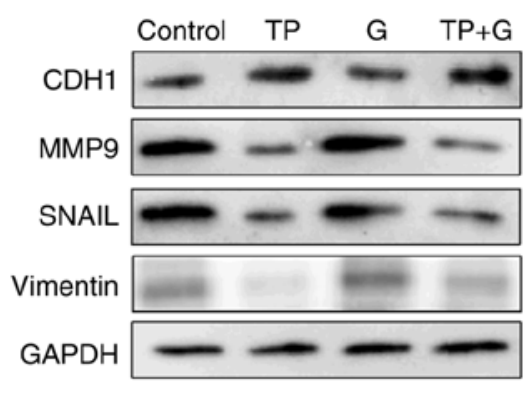

B

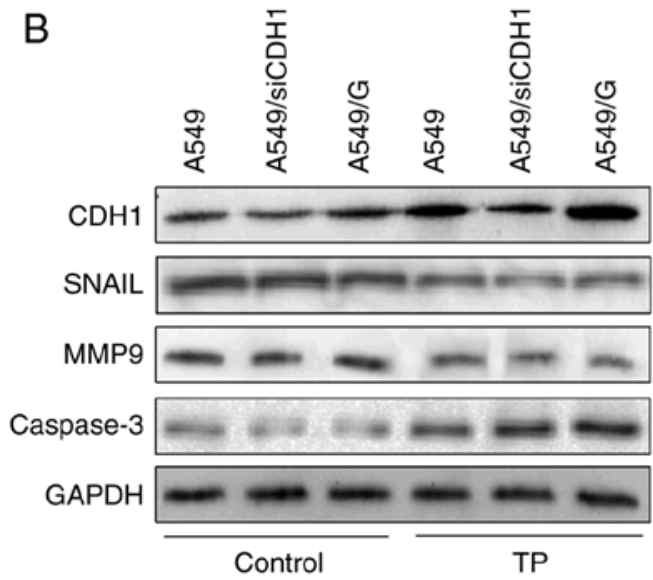

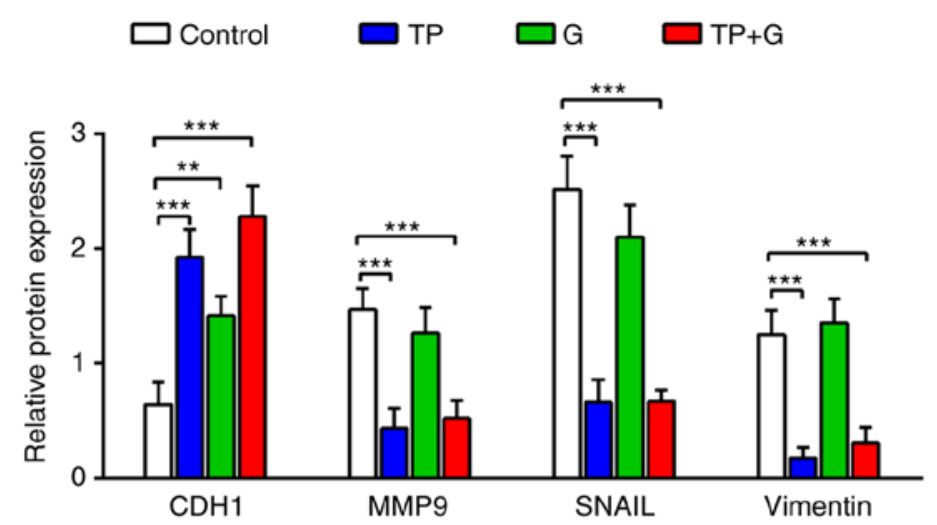

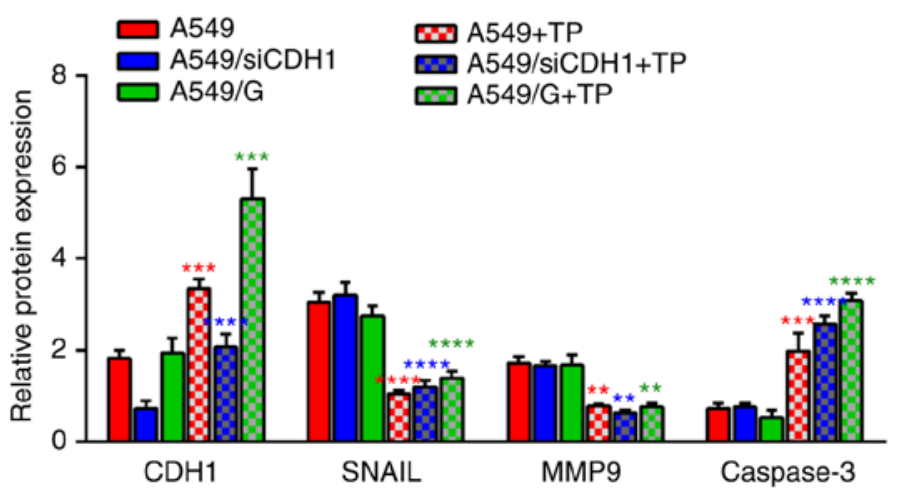

Figure 4. TP regulates CDH1, MMP9, and caspase-3 protein expression. (A) CDH1, MMP9, SNAIL and vimentin proteins in A549 cells treated with TP $(2 \mathrm{ng} / \mathrm{ml})$ and $\mathrm{G}(1.25 \mu \mathrm{g} / \mathrm{ml})$ and their combination were analyzed using western blot analysis. The data for CDH1, MMP9, SNAIL and vimentin protein levels are expressed as the mean \pm SD. Two-way ANOVA and Dunnett's test were used to analyze the statistical differences between the control and drug-treated cells. Statistical differences between the control and treated groups were represented by black '*'. (B) CDH1, MMP9, SNAIL and caspase-3 protein levels in A549, A549/siE-cad and A549/G cells treated with TP (2 ng/ml) were detected by western blotting analysis. The data of protein levels are expressed as the mean \pm SD. GAPDH was used as a loading control. The statistical differences between groups were analyzed by two-way ANOVA combined with Tukey's multiple comparisons test. Statistical differences between control A549 and TP-treated A549 were represented by red '*', statistical differences between A549/ siE-cad and TP-treated A549/siE-cad were represented blue '*', statistical differences between A549/G and TP-treated A549/G were represented green '*'. TP, triptolide; CDH1, E-cadherin; MMP9, matrix metalloproteinase-9; G, gefitinib.

Then, the combination index (CI) was calculated to estimate the synergistic effect of TP and G on A549 cells, according to the method reported by Chou and Talalay (20), in which the synergism is defined by $\mathrm{CI}<1$. The $\mathrm{CI}$ values were 1.01 and 1.06 when A549 cells were treated with TP and G for 24 and $36 \mathrm{~h}$, respectively, while it was 0.84 when the A549 cells were exposed for $48 \mathrm{~h}$ (Table I). This demonstrated an evident synergistic effect of TP and G on A549 cells. Based on this evidence, the effect of TP and $\mathrm{G}$ on cell behavior was next assessed. During the subsequent experiments, the combination of TP $(2 \mathrm{ng} / \mathrm{ml})$ and $\mathrm{G}(1.25 \mu \mathrm{g} / \mathrm{ml})$ were used to treat the A549 cells, which exhibited the synergistic effect of inhibiting the growth of A549 lung adenocarcinoma cells.

TP and G synergistically suppress cell migration of A549 cells. Resistance to gefitinib results in cell metastasis; therefore, the individual or synergistic effect of TP and G on the migration of A549 cells was investigated using Transwell invasion assays. The results in Fig. 2 revealed that treatment with TP and G alone, or in combination, significantly decreased the number of migrated cells $(\mathrm{P}<0.01)$. The number of migrated cells in the $\mathrm{TP}+\mathrm{G}$ group decreased by nearly $60 \%(\mathrm{P}<0.01)$, which was significantly lower than that in the TP- or G-treated cells alone. These data indicated that TP played a suppressive role with $\mathrm{G}$ on the migration of A549 cells, and that TP combined with $\mathrm{G}$ induced a robust decrease in cell migration.

TP suppresses the migration and invasion of gefitinib-resistant A549 cells. To demonstrate the role of TP in gefitinib resistance, a gefitinib-resistant A549 cell line (A549/G) was first established. Deficiency of E-cadherin is implicated in EMT, invasion, and metastasis; therefore, an A549 cell line exhibiting stable interference of E-cadherin expression was also established (A549/siE-cad). Next, the A549/G, A549/siE-cad and control cells were plated in Transwell devices and treated with $2 \mathrm{ng} / \mathrm{ml}$ of TP. The results revealed that E-cadherin interference and gefitinib resistance both led to increased cell migration across the Transwell filters; however, TP markedly suppressed the migration of A549, A549/siE-cad, and A549/G cells (Fig. 3A). The cell invasion assay results revealed that the number of invading A549/siE-cad and A549/G cells was markedly higher than that of the control cells. TP treatment significantly impaired cell invasion of the control, A549/siE-cad, and A549/G cells (Fig. 3B). These results 

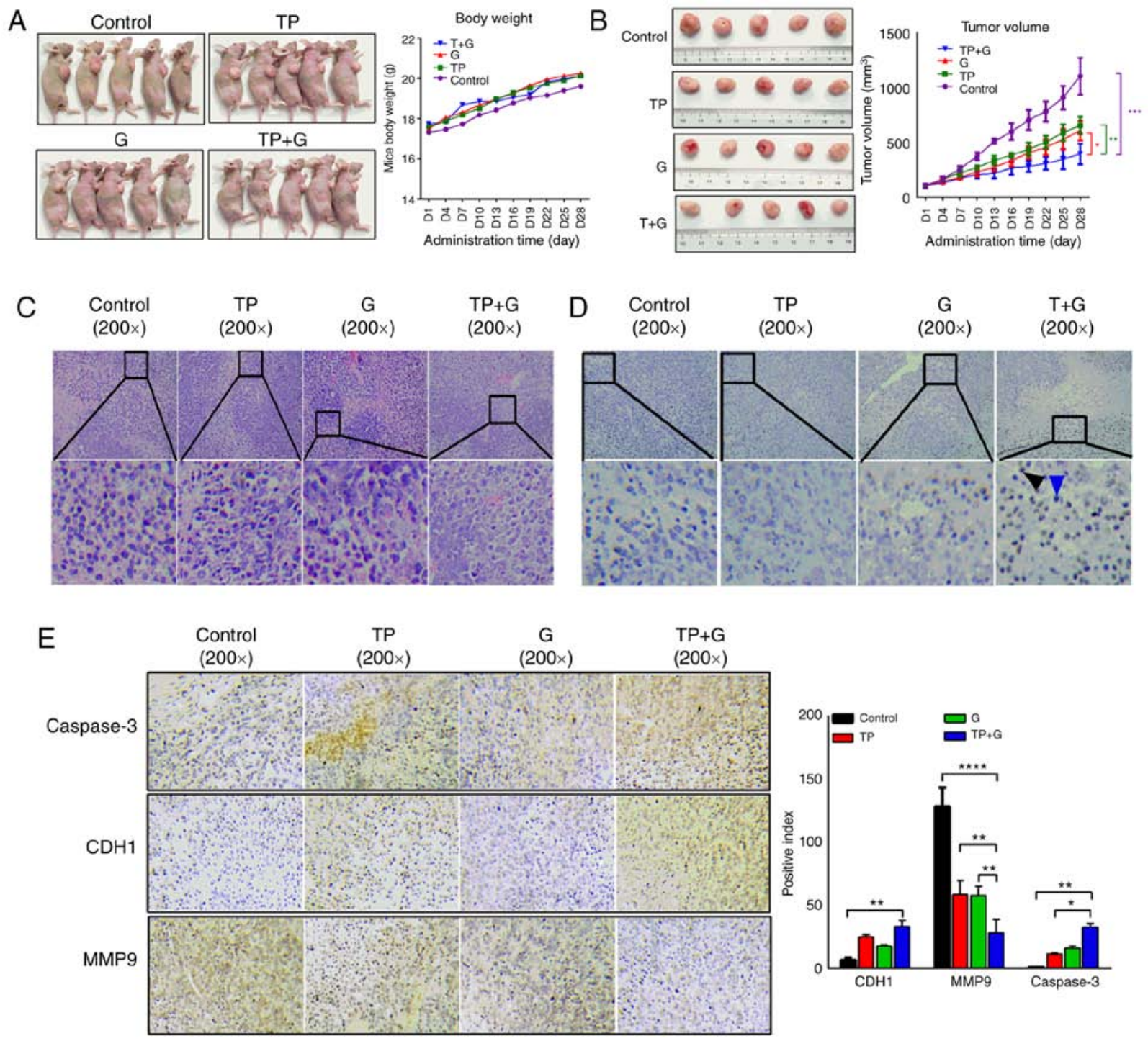

Figure 5. TP and $\mathrm{G}$ combination reveals an enhanced inhibition of A549/siE-cad-induced tumors. (A) Mice bearing A549/siE-cad tumors were divided into four groups of five mice each: The control group [ $\mathrm{NaCl}, 0.1 \mathrm{ml} / 10 \mathrm{~g}$ body weight $(\mathrm{BW})]$, the TP-treated group (TP, $0.5 \mathrm{mg} / \mathrm{kg} \mathrm{BW}$ ), the G-treated group $(\mathrm{G}$, $50 \mathrm{mg} / \mathrm{kg} \mathrm{BW}$ ) and the TP+G-treated group (TP, $0.5 \mathrm{mg} / \mathrm{kg} \mathrm{BW} ; \mathrm{G}, 50 \mathrm{mg} / \mathrm{kg} \mathrm{BW}$ ). Each group was treated with $\mathrm{NaCl}, \mathrm{TP}, \mathrm{G}$, and TP+G, respectively once a day for 4 weeks. The body weight was recorded every three days. (B) The tumor volume was recorded every two days, TP and G, alone or in combination, inhibited the tumor volume at the end of the experiment. Statistical difference between TP+G and control was represented purple “*”, statistical difference between $\mathrm{TP}+\mathrm{G}$ and TP was represented green “**”, statistical difference between $\mathrm{TP}+\mathrm{G}$ and $\mathrm{G}$ was represented red “*”. (C) Representative images of H\&E staining were obtained for the control, TP, G and TP+G groups. (D) TUNEL assays were performed to detect the apoptosis of tumors in the control, TP, G and TP+G groups . The number of apoptotic cells from the control, TP, $G$ and $T P+G$ groups is expressed as the mean \pm SD $(n=3)$. (E) The representative images of IHC staining for $\mathrm{CDH} 1, \mathrm{MMP} 9$ and caspase -3 from the control, TP, G and TP+G groups. The positive index of CDH1, MMP9, and caspase 3 are showed as the mean \pm SD $(\mathrm{n}=3)$. The statistical differences between groups were analyzed by two-way ANOVA combined with Tukey's multiple comparisons test. TP, triptolide; G, gefitinib; CDH1, E-cadherin; H\&E, hematoxylin and eosin; TUNEL, terminal deoxynulceotidyl transferase nick-end-labeling; IHC, immunohistochemistry.

indicated that TP could inhibit cell migration and invasion, and reverse the gefitinib resistance phenotype of A549/siE-cad cells and A549/G cells.

TP reverses the gefitinib resistance of $A 549$ cells by regulating E-cadherin and $M M P$ 9. To determine the underlying molecular mechanism, proteins implicated in EMT were detected using western blotting. The levels of E-cadherin were significantly increased in the drug-treated cells. The E-cadherin expression in the TP+G-treated cells was nearly twice that in the control cells (Fig. 4A). In addition, the matrix metalloproteinase-9 (MMP9), Snail family transcriptional repressor 1 (SNAIL) and vimentin protein levels significantly decreased in the TP- and
$\mathrm{TP}+\mathrm{G}$-treated cells compared with those in the control, and the $\mathrm{G}$ treatment induced a modest reduction of MMP9, SNAIL and vimentin. These results indicated that TP significantly upregulated E-cadherin and downregulated MMP9, SNAIL and vimentin protein expression, and treatment with $\mathrm{TP}+\mathrm{G}$ had a synergistic effect on the levels of E-cadherin.

To determine the role of E-cadherin in TP-treated cells, the E-cadherin levels in A549, A549/siE-cad, and A549/G cells were detected. The results revealed that the E-cadherin level decreased significantly in the A549/siE-cad cells compared with that in the A549 cells and A549/G cells. TP treatment increased the E-cadherin in all three groups, especially in A549 cells (Fig. 4B). The protein expression of MMP9 and 


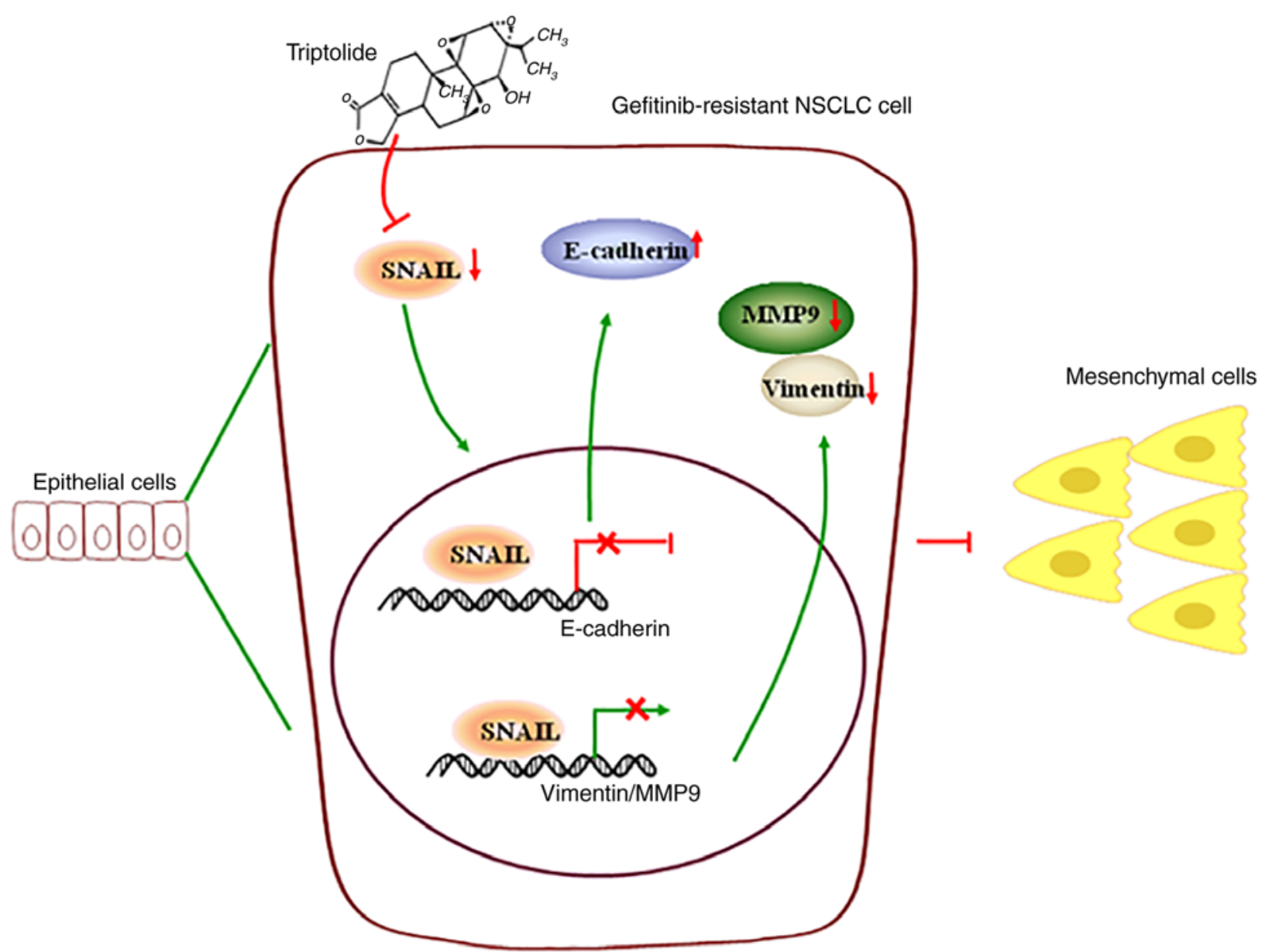

Figure 6. Schematic diagram of the mechanism by which triptolide enhances the sensitivity of gefitinib-resistant lung cancer cells by inhibiting epithelial-mesenchymal transition. Triptolide treatment first decreased SNAIL protein expression. As a transcription factor, the decreased levels of SNAIL induced the upregulation of E-cadherin and downregulation of vimentin and MMP9. These alterations combined to inhibit epithelial-mesenchymal transition. SNAIL, Snail family transcriptional repressor 1; MMP9, matrix metalloproteinase-9.

SNAIL in A549, A549/siE-cad and A549/G cells significantly decreased after TP treatment compared with those in their respective controls. Concurrent, TP treatment significantly increased caspase-3 in A549, A549/siE-cad and A549/G cells. These results indicated that TP suppressed cell migration and invasion of A549, A549/siE-cad, and A549/G cells by regulating the E-cadherin and MMP9 signaling pathway, and induced apoptosis of these cells by increasing the levels of caspase- 3 .

Combination of TP and $G$ synergistically inhibits A549/siE-cad cell xenografts by inducing apoptosis. To further verify the effect of TP on A549 cell tumor induction, an A549/siE-cad tumor-bearing mouse model was produced, and TP, G, and TP/G were administrated to these mice. The results revealed that there were no significant differences in body weight (BW) among the TP, G and TP+G-treated groups. The BW of the three treated groups was slightly heavier than that of the control group, while there was no statistical difference between the treated and control groups (Fig. 5A). With regards to the tumor volume, TP, G and TP/G treatment significantly reduced the tumor volume in a time-dependent manner (Fig. 5B). The tumor volume of the $\mathrm{TP}+\mathrm{G}$ group was significantly smaller than that of TP, G and control groups.
These results indicated that both TP and G have inhibitory effects on tumorigenesis of A549/siE-cad tumor-bearing mice in vivo, and that the inhibitory effect of $\mathrm{TP}+\mathrm{G}$ treatment was greater than that of either $\mathrm{T}$ or $\mathrm{G}$ alone.

Next, H\&E analysis was performed to investigate the pathological changes in the tumors of each group. Treatment with $\mathrm{T}$ or $\mathrm{G}$ alone induced nuclear aberration, cell degradation, and necrosis, and treatment with $\mathrm{T}+\mathrm{G}$ enhanced these effects (Fig. 5C). TUNEL staining revealed that treatment with $\mathrm{T}$ or $\mathrm{G}$ alone induced significant tumor cell apoptosis, and this apoptosis was enhanced by treatment with the $\mathrm{TP}+\mathrm{G}$ combination (Fig. 5D).

Combination of TP and $G$ induces an apoptotic pathway in gefitinib-resistant A549 cells that induces tumors by regulating MMP9 and caspase-3. IHC assays were conducted to investigate the signaling pathways involved in TP-induced inhibition of gefitinib resistance in A549 cells during tumor induction. As revealed in Fig. 5E, the protein level of E-cadherin was significantly increased after treatment with $\mathrm{TP}+\mathrm{G}$, it was also increased in the TP- and G-treated tumor groups, while the statistical difference between the control and monotherapy, or monotherapy and combination therapy was not significant. The protein level of MMP9 was significantly decreased after 
$\mathrm{TP}, \mathrm{G}$ and $\mathrm{TP}+\mathrm{G}$ treatment, and the inhibition in $\mathrm{TP}+\mathrm{G}$ was greater than that in TP or $\mathrm{G}$ alone. In addition, caspase- 3 protein expression increased in the TP-, G- and TP+G-treated tumors, and the increase in the $\mathrm{TP}+\mathrm{G}$ group was higher than that in the TP or G treatment groups. These results indicated that both TP and G could upregulate E-cadherin and caspase-3 expression levels, and downregulate MMP9 protein levels in A549/siE-cad tumor-bearing mice in vivo, however, treatment with $\mathrm{TP}+\mathrm{G}$ exhibited a more potent effect.

\section{Discussion}

Currently, molecular targeted therapy is the preferred treatment for NSCLC. Gefitinib is a typical representative of molecular targeted drugs for lung cancer and belongs to the EGFR-TKI class of drugs (21). However, nearly all patients treated with gefitinib deteriorate due to the emergence of EGFR-TKI acquired resistance, for which no effective therapy is currently available $(22,23)$. Emerging studies have reported that certain Chinese medicines could reduce gefitinib-induced drug resistance, including TP $(24,25)$. However, the role and mechanism of TP in gefitinib-induced drug resistance in NSCLC is unclear. In the present study, it was confirmed that TP inhibited the migration and invasion of A549 cells to a greater extent than $\mathrm{G}$, and this effect was further enhanced using the combination of $\mathrm{G}$ and TP, indicating that TP and gefitinib have a synergistic effect on A549 cells. Subsequently, a gefitinib-resistant A549 cell line (A549/G) was established to investigate whether TP regulated drug resistance. The migration and invasion abilities of gefitinib-resistant cells were enhanced compared with their parental gefitinib-sensitive A549 cells. TP treatment effectively inhibited the migration and invasion of the gefitinib-resistant cells, indicating that TP suppressed gefitinib resistance. These results verified that TP acts as an adjuvant therapeutic agent at low doses to enhance anticancer effectiveness $(9,26,27)$.

Increasing numbers of in vitro and in vivo studies have reported various possible molecular mechanisms of drug resistance to gefitinib, among which $E G F R$ gene amplification and EMT are the most studied (28-30). Rho et al reported that EMT resulting from repeated exposure to gefitinib blunted the sensitivity of A549 cells to EGFR inhibitors (31). Induction of EMT contributed to the decreased efficacy of therapy in primary and acquired resistance to gefitinib (32). E-cadherin is involved in the formation of cell-to-cell adherens junctions that assemble adjacent epithelial cells and maintains their quiescence. Downregulation of E-cadherin is considered the core element of EMT $(33,34)$. Herein, it was revealed that TP significantly increased the levels of E-cadherin both in gefitinib-sensitive and gefitinib-resistant A549 cells, indicating that TP inhibited EMT and increased gefitinib sensitivity by increasing E-cadherin levels. SNAIL, as the core transcription factor regulating EMT, inhibits the expression of $\mathrm{CDH} 1$ by competitive binding to the E-box sequence in the $\mathrm{CDH} 1$ promoter region, and induces mesenchymal proteins such as vimentin and MMP-9, which further promote EMT $(35,36)$. Vimentin was originally identified as a specific marker of mesenchymal tumors; however, it was later revealed to be associated with cancer cell expression and prognosis in patients, and its expression is widely considered as a necessary condition to enhance cancer invasion and metastasis (37). MMP9 is a matrix metalloproteinase secreted by tumor cells that weakens the natural barrier and promotes tumor cell metastasis by degrading the tumor extracellular matrix (ECM). Therefore, a decrease of MMP9 expression plays an important role in inhibiting EMT $(38,39)$. Given the role of SNAIL in the regulation of EMT markers, it was speculated that the decrease in SNAIL levels induced by TP led to a reduction in MMP9 and vimentin, and increased the levels of E-cadherin. The combined effect of these changes resulted in EMT inhibition.

Given the beneficial effects of TP in inhibiting EMT and increasing gefitinib sensitivity, gefitinib-resistant A549 cells were established by interfering with E-cadherin expression and continuous exposure to gefitinib to confirm the ability of TP to increase the sensitivity of gefitinib-resistant cells. The results revealed that the migration and invasion of gefitinib-resistant cells was significantly enhanced. Immunoblotting assays confirmed the loss of E-cadherin, and gain of MMP9 and caspase-3. In addition, TP combined with gefitinib still exhibited an inhibitory effect on the tumors derived from A549/siE-cad cells by upregulating the levels of E-cadherin and caspase-3, and decreasing those of MMP9. Caspase-3 is a pivotal junction protein in apoptotic pathways, which can be activated by other activated caspases and then induces apoptosis $(37,38)$. The present results were consistent with previous studies which revealed that E-cadherin expression potentiates sensitivity to the apoptotic effects of gefitinib $(31,32)$. The increase of E-cadherin is accompanied by the occurrence of apoptosis, which synergistically inhibits tumor growth (40). In a previous study MMP9 inhibition by tetramethylpyrazine was related to vascular endothelial cell apoptosis (41). As for vimentin, it was involved in the emergence of apoptosis induced by peptidylarginine deiminase 2 and TNF- $\alpha(42,43)$. Furthermore, the interference with SNAIL signaling by TPD52L2 induced apoptosis of glioblastoma cells (44). In fact, the inhibition of MMP9, SNAIL, and vimentin proteins always coexists with apoptosis (45). In conclusion, these results indicated that TP could reverse gefitinib resistance of A549 cells by suppressing the EMT signaling pathway and inducing apoptosis.

Acquired resistance to EGFR-TKIs is almost inevitable in patients with NSCLC with EGFR mutations. Management of TKI resistance has become the focus of research to increase the overall survival of these patients. In the present study, it was demonstrated, for the first time to the best of our knowledge, that TP treatment overcomes TKI resistance in vitro and in vivo by reverting EMT. Further studies are required to develop the synergistic anticancer action and drug resistance reversal effect of TP combined with gefitinib for clinical use.

\section{Acknowledgements}

Not applicable.

\section{Funding}

The present study was funded by the Natural Science Foundation of Zhejiang Province (grant. no. LQ17H290001) and the Natural Science Foundation of China (grant. no. 81774026). 


\section{Availability of data and materials}

The analyzed datasets generated during the study are available from the corresponding author on reasonable request.

\section{Authors' contributions}

FL, JW and WW conceived and designed the experiments. FL, JW and XG performed the experiments. HC and XJ collected, analyzed and interpret the data. FL drafted the manuscript. JW and FL revised the manuscript, WW and XG provided important intellectual content. All authors read and approved the final manuscript and agree to be accountable for all aspects of the research in ensuring that the accuracy or integrity of any part of the work are appropriately investigated and resolved.

\section{Ethics approval and consent to participate}

All animal treatment protocols were approved by the Institutional Animal Care and Use Committee of The Tongde Hospital of Zhejiang Province.

\section{Patient consent for publication}

Not applicable.

\section{Competing interests}

The authors declare no competing financial interests.

\section{References}

1. Malhotra J, Jabbour SK and Aisner J: Current state of immunotherapy for non-small cell lung cancer. Transl Lung Cancer Res 6: 196-211, 2017.

2. Liao BC, Lin CC, Lee JH and Yang JC: Optimal management of EGFR-mutant non-small cell lung cancer with disease progression on first-line tyrosine kinase inhibitor therapy. Lung Cancer 110: 7-13, 2017.

3. Liu X, Lu X, Zhen F, Jin S, Yu T, Zhu Q, Wang W, Xu K, Yao J and Guo R: LINC00665 induces acquired resistance to gefitinib through recruiting EZH2 and activating PI3K/AKT pathway in NSCLC. Mol Ther Nucleic Acids 16: 155-161, 2019.

4. Li L, Han R, Xiao H, Lin C, Wang Y, Liu H, Li K, Chen H, Sun F, Yang Z, et al: Metformin sensitizes EGFR-TKI-resistant human lung cancer cells in vitro and in vivo through inhibition of IL-6 signaling and EMT reversal. Clin Cancer Res 20: 2714-2726, 2014.

5. Zhang Y, Wu Z, Yu H, Wang H, Liu G, Wang S and Ji X: Chinese herbal medicine wenxia changfu formula reverses cell adhesionmediated drug resistance via the integrin $\beta 1$-PI3K-AKT pathway in lung cancer. J Cancer 10: 293-304, 2019.

6. Chen P, Huang HP, Wang Y, Jin J, Long WG, Chen K, Zhao XH, Chen CG and Li J: Curcumin overcome primary gefitinib resistance in non-small-cell lung cancer cells through inducing autophagy-related cell death. J Exp Clin Cancer Res 38: 254, 2019.

7. Almaaytah A, Farajallah A, Abualhaijaa A and Al-Balas Q: A3, a Scorpion venom derived peptide analogue with potent antimicrobial and potential antibiofilm activity against clinical isolates of multi-drug resistant gram positive bacteria. Molecules 23: E1603, 2018.

8. Cao F, Gong YB, Kang XH, Lu ZH, Wang Y, Zhao KL, Miao ZH, Liao MJ and Xu ZY: Degradation of MCL-1 by bufalin reverses acquired resistance to osimertinib in EGFR-mutant lung cancer. Toxicol Appl Pharmacol 379: 114662, 2019.

9. Hou ZY, Tong XP, Peng YB, Zhang BK and Yan M: Broad targeting of triptolide to resistance and sensitization for cancer therapy. Biomed Pharmacother 104: 771-780, 2018.
10. Qiu D and Kao PN: Immunosuppressive and anti-inflammatory mechanisms of triptolide, the principal active diterpenoid from the Chinese medicinal herb Tripterygium wilfordii Hook. f. Drugs R D 4: 1-18, 2003.

11. Meng G, Wang W, Chai K, Yang S, Li F and Jiang K: Combination treatment with triptolide and hydroxycamptothecin synergistically enhances apoptosis in A549 lung adenocarcinoma cells through PP2A-regulated ERK, p38 MAPKs and Akt signaling pathways. Int J Oncol 46: 1007-1017, 2015.

12. Xu B, Guo X, Mathew S, Armesilla AL, Cassidy J, Darling JL and Wang W: Triptolide simultaneously induces reactive oxygen species, inhibits NF-kappaB activity and sensitizes 5-fluorouracil in colorectal cancer cell lines. Cancer Lett 291: 200-208, 2010.

13. Xie CQ, Zhou P, Zuo J, Li X, Chen Y and Chen JW: Triptolide exerts pro-apoptotic and cell cycle arrest activity on drug-resistant human lung cancer A549/Taxol cells via modulation of MAPK and PI3K/Akt signaling pathways. Oncol Lett 12: 3586-3590, 2016.

14. Ho JN, Byun SS, Lee S, Oh JJ, Hong SK, Lee SE and Yeon JS: Synergistic antitumor effect of triptolide and cisplatin in cisplatin resistant human bladder cancer cells. J Urol 193: 1016-1022, 2015.

15. Li F, Zhao D, Yang S, Wang J, Liu Q, Jin X and Wang W: ITRAQ-Based proteomics analysis of triptolide on human A549 lung adenocarcinoma cells. Cell Physiol Biochem 45: 917-934, 2018.

16. Kourtidis A, Lu R, Pence LJ and Anastasiadis PZ: A central role for cadherin signaling in cancer. Exp Cell Res 358: 78-85, 2017.

17. Weng CH, Chen LY, Lin YC, Shih JY, Lin YC, Tseng RY, Chiu AC, Yeh YH, Liu C, Lin YT, et al: Epithelial-mesenchymal transition (EMT) beyond EGFR mutations per se is a common mechanism for acquired resistance to EGFR TKI. Oncogene 38: 455-468, 2019.

18. Rastogi I, Rajanna S, Webb A, Chhabra G, Foster B, Webb B and Puri N: Mechanism of c-Met and EGFR tyrosine kinase inhibitor resistance through epithelial mesenchymal transition in non-small cell lung cancer. Biochem Biophys Res Commun 477: 937-944, 2016.

19. Iderzorig T, Kellen J, Osude C, Singh S, Woodman JA, Garcia C and Puri N: Comparison of EMT mediated tyrosine kinase inhibitor resistance in NSCLC. Biochem Biophys Res Commun 496: 770-777, 2018.

20. Chou TC and Talalay P: Quantitative analysis of dose-effect relationships: The combined effects of multiple drugs or enzyme inhibitors. Adv Enzyme Regul 22: 27-55, 1984.

21. Yin J, Hu W, Pan L, Fu W, Dai L, Jiang Z, Zhang F and Zhao J: Let7 and miR17 promote self-renewal and drive gefitinib resistance in non-small cell lung cancer. Oncol Rep 42: 495-508, 2019.

22. Fiore M, Trecca P, Perrone G, Amato M, Righi D, Trodella L, D'Angelillo RM and Ramella S: Histologic transformation to small-cell lung cancer following gefitinib and radiotherapy in a patient with pulmonary adenocarcinoma. Tumori 105: NP12-NP16, 2019.

23. Pao W, Miller VA, Politi KA, Riely GJ, Somwar R, Zakowski MF, Kris MG and Varmus H: Acquired resistance of lung adenocarcinomas to gefitinib or erlotinib is associated with a second mutation in the EGFR kinase domain. PLoS Med 2: e73, 2005.

24. Zhang J, Sun L, Cui J, Wang J, Liu X, Aung TN, Qu Z, Chen Z, Adelson DL and Lin L: Yiqi chutan tang reduces gefitinib-induced drug resistance in non-small-cell lung cancer by targeting apoptosis and autophagy. Cytometry A 97: 70-77, 2019.

25. Meng J, Chang C, Chen Y, Bi F, Ji C and Liu W: EGCG overcomes gefitinib resistance by inhibiting autophagy and augmenting cell death through targeting ERK phosphorylation in NSCLC. Onco Targets Ther 12: 6033-6043, 2019.

26. Wang R, Ma X, Su S and Liu Y: Triptolide antagonized the cisplatin resistance in human ovarian cancer cell line A2780/CP70 via hsa-mir-6751. Future Med Chem 10: 1947-1955, 2018.

27. Han Y, Huang W, Liu J, Liu D, Cui Y, Huang R, Yan J and Lei M: Triptolide inhibits the AR signaling pathway to suppress the proliferation of enzalutamide resistant prostate cancer cells. Theranostics 7: 1914-1927, 2017.

28. Bean J, Brennan C, Shih JY, Riely G, Viale A, Wang L, Chitale D, Motoi N, Szoke J, Broderick S, et al: MET amplification occurs with or without T790M mutations in EGFR mutant lung tumors with acquired resistance to gefitinib or erlotinib. Proc Natl Acad Sci USA 104: 20932-20937, 2007.

29. Schueler J, Tschuch C, Klingner K, Bug D, Peille AL, de Koning L, Oswald E, Klett $\mathrm{H}$ and Sommergruber W: Induction of acquired resistance towards EGFR inhibitor gefitinib in a patient-derived xenograft model of non-small cell lung cancer and subsequent molecular characterization. Cells 8: E740, 2019. 
30. Suda K, Mizuuchi H, Maehara Y and Mitsudomi T: Acquired resistance mechanisms to tyrosine kinase inhibitors in lung cancer with activating epidermal growth factor receptor mutation-diversity, ductility, and destiny. Cancer Metastasis Rev 31: 807-814, 2012.

31. Rho JK, Choi YJ, Lee JK, Ryoo BY, Na II, Yang SH, Kim CH and Lee JC: Epithelial to mesenchymal transition derived from repeated exposure to gefitinib determines the sensitivity to EGFR inhibitors in A549, a non-small cell lung cancer cell line. Lung Cancer 63: 219-226, 2009.

32. Jakobsen KR, Demuth C, Sorensen BS and Nielsen AL: The role of epithelial to mesenchymal transition in resistance to epidermal growth factor receptor tyrosine kinase inhibitors in non-small cell lung cancer. Transl Lung Cancer Res 5: 172-182, 2016.

33. Asakura T, Yamaguchi N, Ohkawa K and Yoshida K: Proteasome inhibitor-resistant cells cause EMT-induction via suppression of E-cadherin by miR-200 and ZEB1. Int J Oncol 46: 2251-2260, 2015.

34. Gloushankova NA, Zhitnyak IY and Rubtsova SN: Role of epithelial-mesenchymal transition in tumor progression. Biochemistry (Mosc) 83: 1469-1476, 2018.

35. Papiewska-Pajak I, Kowalska MA and Boncela J: Expression and activity of SNAIL transcription factor during epithelial to mesenchymal transition (EMT) in cancer progression. Postepy Hig Med Dosw (Online) 70: 968-980, 2016

36. Shimokawa M, Haraguchi M, Kobayashi W, Higashi Y, Matsushita S, Kawai K, Kanekura T and Ozawa M: The transcription factor Snail expressed in cutaneous squamous cell carcinoma induces epithelial-mesenchymal transition and down-regulates COX-2. Biochem Biophys Res Commun 430: 1078-1082, 2013.

37. Richardson AM, Havel LS, Koyen AE, Konen JM, Shupe J, Wiles WG IV, Martin WD, Grossniklaus HE, Sica G, Gilbert-Ross M and Marcus AI: Vimentin is required for lung adenocarcinoma metastasis via heterotypic tumor cell-cancer-associated fibroblast interactions during collective invasion. Clin Cancer Res 24: 420-432, 2018.

38. Huang $M$ and Xin W: Matrine inhibiting pancreatic cells epithelial-mesenchymal transition and invasion through ROS/NF-кB/MMPs pathway. Life Sci 192: 55-61, 2018.
39. Sun Q, Yang Z, Li P, Wang X, Sun L, Wang S, Liu M and Tang H: A novel miRNA identified in GRSF1 complex drives the metastasis via the PIK3R $3 / \mathrm{AKT} / \mathrm{NF}-\kappa \mathrm{B}$ and TIMP3/MMP9 pathways in cervical cancer cells. Cell Death Dis 10: 636, 2019.

40. Han B, Zhang YY, Xu K, Bai Y, Wan LH, Miao SK, Zhang KX, Zhang HW, Liu Y and Zhou LM: NUDCD1 promotes metastasis through inducing EMT and inhibiting apoptosis in colorectal cancer. Am J Cancer Res 8: 810-823, 2018.

41. Hu JZ, Wang XK, Cao Y, Li DZ, Wu TD, Zhang T, Xu DQ and Lu HB: Tetramethylpyrazine facilitates functional recovery after spinal cord injury by inhibiting MMP2, MMP9, and vascular endothelial cell apoptosis. Curr Neurovasc Res 14: 110-116, 2017.

42. Hsu PC, Liao YF, Lin CL, Lin WH, Liu GY and Hung HC: Vimentin is involved in peptidylarginine deiminase 2-induced apoptosis of activated Jurkat cells. Mol Cells 37: 426-34, 2014.

43. Yang L, Tang L, Dai F, Meng G, Yin R, Xu X and Yao W: Raf-1/CK 2 and RhoA/ROCK signaling promote TNF- $\alpha$-mediated endothelial apoptosis via regulating vimentin cytoskeleton. Toxicology 389: 74-84, 2017.

44. Qiang Z, Jun-Jie L, Hai W, Hong L Hong L, Bing-Xi L, Lei C, Wei X, Ya-Wei L, Huang A, Song-Tao Q and Yun-Tao L: TPD52L2 impacts proliferation, invasiveness and apoptosis of glioblastoma cells via modulation of wnt $/ \beta$-catenin/snail signaling. Carcinogenesis 39: 214-224, 2018.

45. Bao X, Ren T, Huang Y, Ren C, Yang K, Zhang H and Guo W: Bortezomib induces apoptosis and suppresses cell growth and metastasis by inactivation of Stat 3 signaling in chondrosarcoma. Int J Oncol 50: 477-486, 2017.

This work is licensed under a Creative Commons Attribution-NonCommercial-NoDerivatives 4.0 International (CC BY-NC-ND 4.0) License. 